\title{
Anti-acid therapy in idiopathic pulmonary fibrosis: insights from the INPULSIS ${ }^{\circledast}$ trials
}

\author{
Ulrich Costabel ${ }^{1}$, Jürgen Behr ${ }^{2}$, Bruno Crestani ${ }^{3}$, Wibke Stansen ${ }^{4}$, Rozsa Schlenker-Herceg ${ }^{5}$, Susanne Stowasser ${ }^{4}$ \\ and Ganesh Raghu ${ }^{6^{*}}$
}

\begin{abstract}
Background: The benefits and risks of anti-acid medication in patients with idiopathic pulmonary fibrosis (IPF) remain a topic of debate. We investigated whether use of anti-acid medication at baseline was associated with differences in the natural course of disease or influenced the treatment effect of nintedanib in patients with IPF.

Methods: Post-hoc analyses of outcomes in patients receiving versus not receiving anti-acid medication (proton pump or histamine-2 receptor inhibitor) at baseline using pooled data from the two Phase III randomized placebo-controlled INPULSIS ${ }^{\oplus}$ trials of nintedanib in patients with IPF.
\end{abstract}

Results: At baseline, 406 patients were receiving anti-acid medication (244 nintedanib; 162 placebo) and 655 were not (394 nintedanib; 261 placebo). In an analysis of the natural course of IPF by anti-acid medication use at baseline, the adjusted annual rate of decline in FVC was - $252.9 \mathrm{~mL} /$ year in placebo-treated patients who were receiving anti-acid medication at baseline and - $205.4 \mathrm{~mL} /$ year in placebo-treated patients who were not (difference of $-47.5 \mathrm{~mL} /$ year [95\% Cl: -105.1, 10.1]; $p=0.1057)$. In an analysis of the potential influence of anti-acid medication use on the treatment effect of nintedanib, the adjusted annual rates of decline in FVC were $-124.4 \mathrm{~mL} /$ year in the nintedanib group and $252.9 \mathrm{~mL} /$ year in the placebo group (difference of $128.6 \mathrm{~mL} /$ year [95\% Cl: 74.9, 182.2]) in patients who were receiving anti-acid medication at baseline and $-107.0 \mathrm{~mL} /$ year in the nintedanib group and $-205.3 \mathrm{~mL} /$ year in the placebo group (difference of $98.3 \mathrm{~mL} /$ year [95\% Cl: 54.1, 142.5]) in patients who were not (treatment-by-time-by-subgroup interaction $p=0.3869$ ). The proportions of patients who had $\geq 1$ investigator-reported acute exacerbation were $11.7 \%$ and $5.0 \%$ in placebo-treated patients, and $4.9 \%$ and $4.8 \%$ of nintedanib-treated patients, among patients who were and were not receiving anti-acid medication at baseline, respectively.

Conclusions: In post-hoc analyses of data from the INPULSIS ${ }^{\oplus}$ trials, anti-acid medication use at baseline was not associated with a more favorable course of disease, and did not impact the treatment effect of nintedanib, in patients with IPF.

Trial registration: ClinicalTrials.gov identifiers: NCT01335464 and NCT01335477.

\section{Background}

Idiopathic pulmonary fibrosis (IPF) is a specific form of progressive fibrosing interstitial lung disease characterized by worsening lung function and dyspnea [1]. IPF is believed to develop as a result of an aberrant wound healing response to epithelial injury, in which activated alveolar epithelial cells release fibrogenic growth factors, promoting fibroblast proliferation and transformation to myofibroblasts and excess deposition of extracellular

\footnotetext{
* Correspondence: graghu@uw.edu

${ }^{6}$ University of Washington, Seattle, WA, USA

Full list of author information is available at the end of the article
}

matrix [2]. IPF typically presents during the sixth or seventh decade and is more common in men than in women [1]. The natural history of IPF is variable but its prognosis is poor [3]. Acute deteriorations in respiratory function, known as acute exacerbations, are a common feature of the clinical course of IPF and a major cause of morbidity and mortality [4].

Gastroesophageal reflux disease (GERD) is known to be a common comorbidity in patients with IPF, but its reported prevalence varies widely according to the definition used [5]. In the INSIGHTS-IPF registry of patients with IPF in Germany, 29\% of patients reported GERD

(C) The Author(s). 2018 Open Access This article is distributed under the terms of the Creative Commons Attribution 4.0 International License (http://creativecommons.org/licenses/by/4.0/), which permits unrestricted use, distribution, and 
on enrollment [6], while in a prospective study of 65 patients with IPF, acid gastroesophageal reflux occurred in $87 \%$ of patients subjected to $24-\mathrm{h} \mathrm{pH}$ monitoring [7]. It has been hypothesized that microaspiration caused by GERD plays a role in the pathogenesis of IPF by causing injury to the lung epithelium and the initiation of inflammatory cascades [8-11] but a causal relationship between GERD and IPF has not been established.

Proton pump inhibitors used to treat GERD have pleiotropic antioxidant and anti-inflammatory effects [12]. Proton pump inhibitors target the $\mathrm{H}+/ \mathrm{K}+$ ATPase, which has recently been shown to be expressed in the hyperplastic alveolar epithelium in patients with IPF [13]. Use of anti-acid medication has been associated with a decreased rate of decline in FVC and improved survival in some observational studies in patients with IPF [14, 15]. Surgical intervention to treat GERD (i.e. Nissen fundoplication) in patients with IPF has also been associated with improved survival $[14,16]$. The latest international clinical practice guidelines for IPF included a conditional recommendation for the use of anti-acid therapy in patients with asymptomatic GERD, based on very low quality evidence [17]. However, there are no data from randomized controlled trials showing an improvement in outcomes in patients with IPF treated with anti-acid medication and the benefits and risks of anti-acid medication in patients with IPF remain a topic of debate [18-20].

Nintedanib is an intracellular inhibitor of tyrosine kinases that has been approved for the treatment of IPF in many countries and regions, including the US, Europe and Asia. In the latest international clinical practice guidelines for IPF [17], nintedanib received a conditional recommendation for use based on data from three randomized controlled trials [21, 22]. In the two replicate Phase III INPULSIS ${ }^{\circ}$ trials, nintedanib slowed disease progression in patients with IPF by reducing the rate of decline in forced vital capacity (FVC) by about 50\% [22]. The most frequently reported adverse events in patients treated with nintedanib were gastrointestinal, particularly diarrhea.

We conducted post-hoc analyses of data from the INPULSIS ${ }^{\circ}$ trials to investigate whether use of anti-acid medication at baseline was associated with differences in the natural course of disease or influenced the treatment effect of nintedanib in patients with IPF.

\section{Methods}

The design of the INPULSIS ${ }^{\circ}$ trials has been described [22]. Briefly, participants had to have been diagnosed with IPF within the previous 5 years and to have an FVC of $\geq 50 \%$ predicted and a diffusing capacity of the lungs for carbon monoxide (DLco) of $30-79 \%$ predicted. In the absence of a surgical lung biopsy, patients were required to have honeycombing and/or a combination of traction bronchiectasis and reticulation in the absence of atypical features of usual interstitial pneumonia on high-resolution computed tomography (HRCT). Patients were randomized $3: 2$ to receive nintedanib $150 \mathrm{mg}$ bid or placebo for 52 weeks, with a follow-up visit 4 weeks later. The primary endpoint was the annual rate of decline in FVC ( $\mathrm{mL} /$ year), analyzed using a random coefficient regression model including sex, age and height as covariates. Key secondary endpoints were time to first investigator-reported acute exacerbation (defined in [22]) and change from baseline in St George's Respiratory Questionnaire (SGRQ) total score, both over 52 weeks. Time to first acute exacerbation was analyzed using the log rank test, with hazard ratios and confidence intervals obtained using the Cox's proportional hazards model adjusted for sex, age and height. Change from baseline in SGRQ total score was analyzed using a mixed model for repeated measures including treatment and visit as fixed effects, baseline score as a covariate, and treatment-by-visit and baseline score-by-visit as interaction terms.

The post-hoc analyses presented in this paper were based on pooled data from both INPULSIS ${ }^{\circ}$ trials and included all patients who received $\geq 1$ dose of study drug. Anti-acid medications comprised proton pump inhibitors and histamine- 2 receptor antagonists. Patients who took anti-acid medication before and also after the first intake of trial medication (based on case report forms) were considered to be using anti-acid medication at baseline. The presence of GERD was assessed solely based on the comorbidities reported by the patient and provided in the case report form.

To evaluate whether anti-acid medication use at baseline was associated with differences in the natural course of IPF, analyses of the annual rate of decline in FVC (mL/year) and the time to absolute decline in FVC $\geq 10 \%$ predicted or death over 52 weeks were conducted in patients treated with placebo who were versus were not receiving anti-acid medication at baseline. A Cox regression model with terms for trial, subgroup, sex, age and height was used to assess time to absolute decline in FVC $\geq 10 \%$ predicted or death over 52 weeks. The original statistical approach for the annual rate of decline in FVC was repeated, but with an interaction term time-by-baseline anti-acid medication use included as a fixed effect in the model.

To evaluate the potential influence of anti-acid medication at baseline on the treatment effect of nintedanib, analyses of the annual rate of decline in FVC (mL/year), time to first investigator-reported acute exacerbation, change from baseline in SGRQ total score, time to absolute decline in FVC $\geq 5 \%$ predicted or death, or FVC $\geq 10 \%$ predicted or death, over 52 weeks were conducted in patients who were versus were not receiving anti-acid 
medication at baseline. For the annual rate of decline in FVC, the term subgroup and the interaction terms treatment-by-subgroup, time-by-subgroup and treatmentby-time-by-subgroup were included in the original model. For time to first investigator-reported acute exacerbation and change from baseline in SGRQ total score, the term subgroup and the interaction term treatment-by-subgroup were included in the model. Time to absolute decline in FVC $\geq 5 \%$ predicted or death, or FVC $\geq 10 \%$ predicted or death was analyzed using a Cox regression model with the term subgroup and the interaction term treatment-bysubgroup included in the model. The interaction $p$-value is an indicator of the potential difference in the treatment effect of nintedanib versus placebo between the subgroups. Statistical Analysis System (SAS) version 9.4 was used for all the analyses.

Safety was assessed via clinical and laboratory evaluation and the recording of adverse events with onset after the first dose and up to 28 days after the last dose of study drug. Adverse events were coded according to the Medical Dictionary for Regulatory Activities version 16.1. Safety analyses were descriptive.

\section{Results}

\section{Patients}

A total of $406(38 \%)$ patients were receiving anti-acid medication at baseline (244 in the nintedanib group, 162 in the placebo group) and 655 patients were not (394 in the nintedanib group, 261 in the placebo group). Of the patients receiving anti-acid medication at baseline, 226 (93\%) in the nintedanib group and 147 (91\%) in the placebo group were receiving $\geq 1$ proton pump inhibitor; 25 patients $(10 \%)$ in the nintedanib group and 22 patients
(14\%) in the placebo group were receiving $\geq 1$ histamine- 2 receptor antagonist (Additional file 1).

Baseline characteristics were generally similar between the subgroups by use of anti-acid medication use at baseline, but a greater proportion of White than Asian patients were receiving anti-acid medication and SGRQ total score was higher (indicating worse quality of life) in patients receiving anti-acid medication (Table 1). Of the patients receiving anti-acid medication at baseline, $52.0 \%$ and $51.2 \%$ of patients in the nintedanib and placebo groups, respectively, reported having GERD (Additional file 2).

In patients receiving anti-acid medication at baseline, mean (SD) duration of exposure to study medication was 10.1 (3.5) months in the nintedanib group and 10.7 (2.8) months in the placebo group. In patients not receiving anti-acid medication at baseline, mean (SD) duration of exposure in these groups was 10.4 (3.3) months and 10.9 (2.8) months, respectively.

\section{Annual rate of decline in FVC}

In the evaluation of whether there was a difference in the natural course of IPF by anti-acid medication use at baseline, the adjusted annual rate of decline in FVC was - $252.9 \mathrm{~mL} /$ year in placebo-treated patients who were receiving anti-acid medication at baseline and$205.4 \mathrm{~mL} /$ year in placebo-treated patients who were not receiving anti-acid medication at baseline (difference of - $47.5 \mathrm{~mL} /$ year [95\% CI: -105.1, 10.1]; $p=0.1057$ ).

In analyses to investigate the potential influence of anti-acid medication use at baseline on the treatment effect of nintedanib, the adjusted annual rates of decline in FVC were $-124.4 \mathrm{~mL} /$ year in the nintedanib group and $-252.9 \mathrm{~mL} /$ year in the placebo group (difference of

Table 1 Baseline characteristics

\begin{tabular}{|c|c|c|c|c|}
\hline & \multicolumn{2}{|c|}{ Anti-acid medication at baseline } & \multicolumn{2}{|c|}{ No anti-acid medication at baseline } \\
\hline & Nintedanib $(n=244)$ & Placebo $(n=162)$ & Nintedanib $(n=394)$ & Placebo $(n=261)$ \\
\hline Age, years, mean (SD) & $67.4(8.3)$ & $68.0(7.4)$ & $66.1(8.0)$ & $66.4(8.1)$ \\
\hline Male, n (\%) & $179(73.4)$ & $124(76.5)$ & $328(83.2)$ & $210(80.5)$ \\
\hline \multicolumn{5}{|l|}{ Race, n (\%) } \\
\hline White & $164(67.2)$ & $117(72.2)$ & $196(49.7)$ & $131(50.2)$ \\
\hline Asian & $40(16.4)$ & $28(17.3)$ & $154(39.1)$ & $100(38.3)$ \\
\hline Black & $0(0.0)$ & $0(0.0)$ & $2(0.5)$ & $0(0.0)$ \\
\hline Missing* & $40(16.4)$ & $17(10.5)$ & $42(10.7)$ & $30(11.5)$ \\
\hline Former or current smoker, n (\%) & $170(69.7)$ & $121(74.7)$ & $294(74.6)$ & $180(69.0)$ \\
\hline $\mathrm{FVC}, \mathrm{mL}$, mean (SD) & $2643(712)$ & $2679(818)$ & $2757(781)$ & $2758(806)$ \\
\hline FVC, \% predicted, mean (SD) & $80.3(17.4)$ & $78.4(17.3)$ & $79.4(17.7)$ & $79.8(18.8)$ \\
\hline $\mathrm{FEV}_{1} / \mathrm{FVC}, \%$, mean (SD) & $82.0(5.5)$ & $81.9(5.9)$ & $81.4(6.1)$ & $81.5(6.0)$ \\
\hline DLco, \% predicted, mean (SD) & $47.6(15.1)$ & $48.1(14.3)$ & $47.3(12.4)$ & $46.3(12.8)$ \\
\hline SGRQ total score, mean $(\mathrm{SD})^{\dagger}$ & $43.4(18.7)$ & $44.1(17.9)$ & $37.2(19.1)$ & $36.8(18.4)$ \\
\hline
\end{tabular}

*In France, regulation did not permit the collection of data on race. ${ }^{\dagger} n=234$ for nintedanib and $n=160$ for placebo in anti-acid medication at baseline subgroup; $n=390$ for nintedanib and $n=259$ for placebo in no anti-acid medication at baseline subgroup 
$128.6 \mathrm{~mL} /$ year [95\% CI: 74.9, 182.2]) in patients who were receiving anti-acid medication at baseline and$107.0 \mathrm{~mL} /$ year in the nintedanib group and $-205.3 \mathrm{~mL} /$ year in the placebo group (difference of $98.3 \mathrm{~mL} /$ year [95\% CI: 54.1, 142.5]) in patients who were not (Fig. 1). There was no significant treatment-by-time-by-subgroup interaction $(p=0.3869)$, indicating that the treatment effect was the same in both subgroups (Fig. 1).

\section{Disease progression}

There was a numerical but not significant difference in the time to absolute decline in FVC $\geq 10 \%$ predicted or death between placebo-treated patients who were taking anti-acid medication at baseline versus were not receiving anti-acid medication at baseline (HR 1.33 [95\% CI: $0.98,1.80] ; p=0.0661)$. In total, $47.5 \%$ and $37.5 \%$ of placebo-treated patients who were and were not receiving anti-acid medication at baseline, respectively, had a decline in FVC $\geq 10 \%$ predicted or died, while $75.3 \%$ and $69.3 \%$ of placebo-treated patients in these subgroups, respectively, had a decline in FVC $\geq 5 \%$ predicted or died.

In analyses to investigate the potential influence of anti-acid medication use at baseline on the treatment effect of nintedanib, the HRs for time to decline in FVC $\geq 10 \%$ predicted or death were 0.60 (95\% CI: $0.43,0.82$ ) in patients who were receiving anti-acid medication at baseline and 0.60 (95\% CI: 0.45, 0.79) in patients who were not (treatment-by-subgroup interaction $p=0.9808$ ). The HRs for time to decline in FVC $\geq 5 \%$ predicted or death were 0.61 (95\% CI: 0.48, 0.78) and 0.60 (95\% CI: $0.49,0.73$ ) in these groups, respectively (treatment-bysubgroup interaction $p=0.8661$ ). For both disease progression endpoints, the criterion reached was FVC decline rather than death in most patients (Table 2).

\section{Investigator-reported acute exacerbations}

Kaplan-Meier estimates of time to first acute exacerbation are presented in Fig. 2. In the placebo group, 19 patients (11.7\%) and 13 patients (5.0\%) who were and were not receiving anti-acid medication at baseline, respectively, had $\geq 1$ acute exacerbation. In the nintedanib group, 12 patients $(4.9 \%)$ and 19 patients $(4.8 \%)$ who were and were not receiving anti-acid medication at baseline, respectively, had $\geq 1$ acute exacerbation. The HR for nintedanib versus placebo for time to first acute exacerbation was 0.40 (95\% CI: $0.19,0.83)$ in patients who were receiving anti-acid medication at baseline and 0.99 (95\% CI: 0.49, $2.00)$ in patients who were not. Although there was no significant treatment-by-subgroup interaction $(p=0.0949)$, there appeared to be a numerical difference, not ruling out a potential difference in the treatment effect of nintedanib between the subgroups.

\section{SGRQ total score}

In the placebo group, the adjusted mean changes from baseline in SGRQ total score over 52 weeks were 6.54 and 4.04 in patients who were and were not receiving anti-acid medication at baseline, respectively; in the nintedanib group, the adjusted mean changes from baseline were 4.83 and 2.80 in these subgroups, respectively (Fig. 3). There was no significant treatment-by-subgroup interaction $(p=0.8536)$, indicating that the treatment effect was the same in both subgroups.

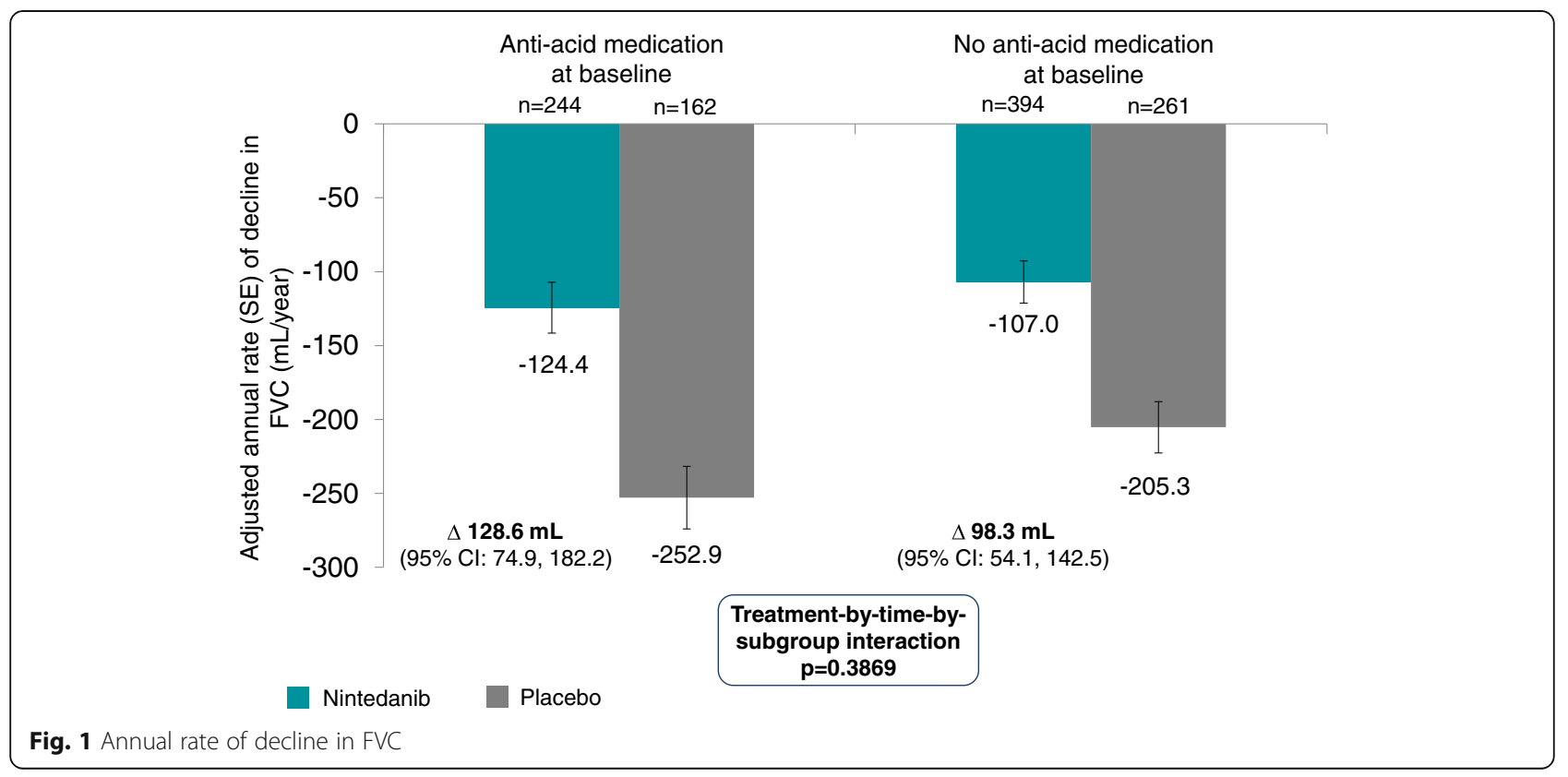


Table 2 Disease progression

\begin{tabular}{|c|c|c|c|c|}
\hline \multirow[t]{2}{*}{ N (\%) } & \multicolumn{2}{|c|}{ Anti-acid medication at baseline } & \multicolumn{2}{|c|}{ No anti-acid medication at baseline } \\
\hline & Nintedanib $(n=244)$ & Placebo $(n=162)$ & Nintedanib $(n=394)$ & Placebo $(n=261)$ \\
\hline Absolute decline in FVC $\geq 10 \%$ predicted or death & $77(31.6)$ & $77(47.5)$ & $96(24.4)$ & $98(37.5)$ \\
\hline \multicolumn{5}{|l|}{ Criterion reached first } \\
\hline Absolute decline in FVC $\geq 10 \%$ predicted & $67(27.5)$ & $65(40.1)$ & $81(20.6)$ & $88(33.7)$ \\
\hline Death & $10(4.1)$ & $12(7.4)$ & $15(3.8)$ & $10(3.8)$ \\
\hline Absolute decline in FVC $\geq 5 \%$ predicted or death & $135(55.3)$ & $122(75.3)$ & $195(49.5)$ & $181(69.3)$ \\
\hline \multicolumn{5}{|l|}{ Criterion reached first } \\
\hline Absolute decline in FVC $\geq 5 \%$ predicted & $129(52.9)$ & $117(72.2)$ & $188(47.7)$ & $175(67.0)$ \\
\hline Death & $6(2.5)$ & $5(3.1)$ & $7(1.8)$ & $6(2.3)$ \\
\hline
\end{tabular}

\section{Adverse events}

A summary of adverse events is presented in Table 3. Diarrhea was the most frequent adverse event in nintedanib-treated patients, reported in $60.7 \%$ and $63.5 \%$ of patients who were and were not receiving anti-acid medication at baseline compared with $17.3 \%$ and $19.2 \%$ of placebo-treated patients in these groups, respectively. Permanent discontinuation of study medication due to diarrhea was more frequent in nintedanib-treated patients who were receiving anti-acid medication at baseline than those were not $(6.6 \%$ versus $3.0 \%)$. Pneumonia was reported in 5.3\% and $7.4 \%$ of nintedanib- and placebo-treated patients who were receiving anti-acid medication at baseline compared with $4.1 \%$ and $4.6 \%$ of nintedanib- and placebo-treated patients who were not, respectively. Serious adverse events were reported in $35.7 \%$ and $37.0 \%$ of nintedanib- and placebo-treated patients who were receiving anti-acid medication at baseline compared with $27.2 \%$ and $25.7 \%$ of nintedanib- and placebo-treated patients who were not, respectively (Additional file 3 ).

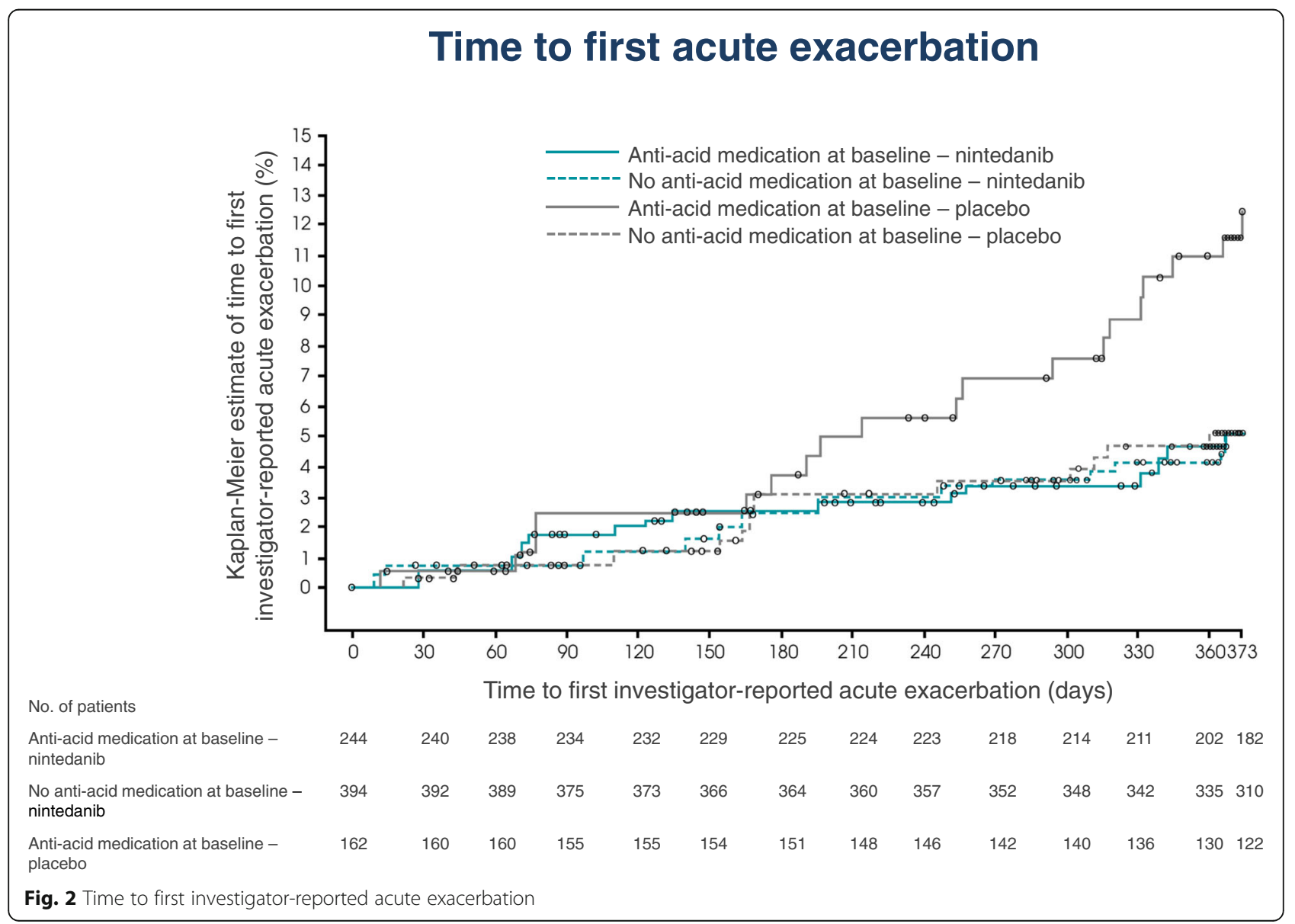




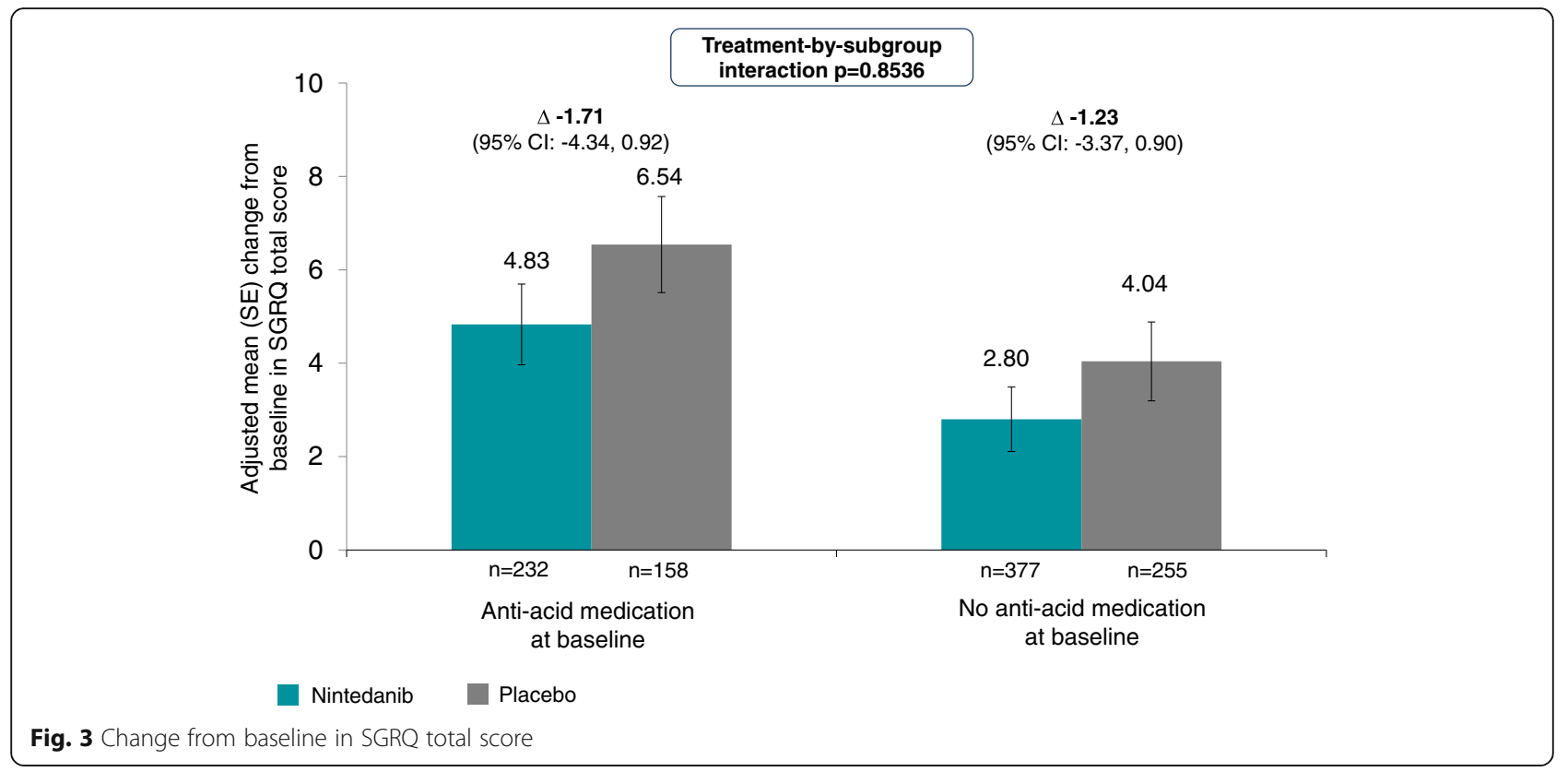

\section{Discussion}

The results of this post-hoc subgroup analysis of data from the INPULSIS ${ }^{\circ}$ trials showed that use of anti-acid medication at baseline generally did not influence the treatment effect of nintedanib in patients with IPF. In the placebo group, the annual rate of decline in FVC was numerically higher in patients who were receiving anti-acid medication at baseline than in those who were not $(-252.9$ vs $-205.4 \mathrm{~mL} / \mathrm{year}$; difference of $47.5 \mathrm{~mL} /$ year [95\% CI: $-105.1,10.1] ; p=0.1057)$ and a greater proportion of patients receiving anti-acid medication at baseline experienced decline in FVC $\geq 10 \%$ predicted or died over 52 weeks (47.5\% vs $37.5 \%)$. These findings should be interpreted with caution given that these analyses were conducted post-hoc; that patients were not randomized according to reported use of anti-acid medication; that information on the type, dose, and duration of anti-acid medication used throughout (or prior to) the study are lacking; that the efficacy of anti-acid medication in suppressing acid reflux is not known, and that it is unknown whether the patients were taking anti-acid medication to treat symptomatic GERD (acid or non-acid), assumed silent GERD, or even IPF. Similar caveats apply to the interpretation of data from a post-hoc analysis of pooled data from three randomized trials of pirfenidone in patients with IPF, in which use of anti-acid therapy at baseline was not associated with a difference in the occurrence of disease progression in either the placebo group $[18,23]$ or the pirfenidone group [24].

Elevated pepsin levels in bronchoalveolar lavage fluid have been documented in patients manifesting acute exacerbations of IPF [8]. In a prospective observational study of data from placebo-treated patients with IPF in the IPFnet trials, there were no adjudicated acute exacerbations in the 124 patients who used anti-acid medication at baseline (of whom 117 continued to take it for the entire study period) versus 9 acute exacerbations in the 118 patients who did not use anti-acid medication at baseline [15]. In contrast, in our post-hoc analysis of data from the INPULSIS ${ }^{\circ}$ trials, acute exacerbations reported by the site investigators occurred in a greater proportion of placebo-treated patients who were receiving anti-acid medication at baseline than in those who were not (11.7\% [19 patients] versus 5.0\% [13 patients]). An increased risk of investigator-reported acute exacerbations (and adjudicated confirmed or suspected acute exacerbations) was also observed in a risk factor analysis based on pooled data from these trials [25]. There are multiple hypotheses that may explain these findings. Patients who were receiving anti-acid medication at baseline may have had a greater extent of IPF than patients who were not. The patients receiving anti-acid medication at baseline had worse health-related quality of life at baseline according to SGRQ total score and a greater frequency of fatal adverse events, but did not have greater lung function impairment based on FVC or DLco. Secondly, it is possible that the increased frequency of acute exacerbations in patients taking anti-acid medication at baseline may be due to insufficiently controlled microaspiration in patients who had co-existing GERD. Abnormal acid gastro-oesphageal reflux has been documented in patients with IPF taking proton pump inhibitors [26], and the use of antiacid medication may not have fully suppressed acid reflux in patients in these trials who had concomitant GERD. Thirdly, it may be hypothesized that 
Table 3 Adverse events

\begin{tabular}{|c|c|c|c|c|}
\hline & \multicolumn{2}{|c|}{ Anti-acid medication at baseline } & \multicolumn{2}{|c|}{ No anti-acid medication at baseline } \\
\hline & Nintedanib $(n=244)$ & Placebo $(n=162)$ & Nintedanib $(n=394)$ & Placebo $(n=261)$ \\
\hline Any adverse event(s) & $235(96.3)$ & $152(93.8)$ & $374(94.9)$ & $227(87.0)$ \\
\hline \multicolumn{5}{|l|}{ Most frequent adverse event(s)* } \\
\hline Diarrhea & $148(60.7)$ & $28(17.3)$ & $250(63.5)$ & $50(19.2)$ \\
\hline Nausea & $66(27.0)$ & $14(8.6)$ & $90(22.8)$ & $14(5.4)$ \\
\hline Nasopharyngitis & $32(13.1)$ & $24(14.8)$ & $55(14.0)$ & $44(16.9)$ \\
\hline Cough & $41(16.8)$ & $29(17.9)$ & $44(11.2)$ & $28(10.7)$ \\
\hline Vomiting & $36(14.8)$ & $4(2.5)$ & $38(9.6)$ & $7(2.7)$ \\
\hline Decreased appetite & $27(11.1)$ & $9(5.6)$ & $41(10.4)$ & $15(5.7)$ \\
\hline Bronchitis & $35(14.3)$ & $18(11.1)$ & $32(8.1)$ & $27(10.3)$ \\
\hline Progression of $\mathrm{PF}^{\dagger}$ & $28(11.5)$ & $30(18.5)$ & $36(9.1)$ & $31(11.9)$ \\
\hline Weight decreased & $26(10.7)$ & $5(3.1)$ & $36(9.1)$ & $10(3.8)$ \\
\hline Upper respiratory tract infection & $20(8.2)$ & $18(11.1)$ & $38(9.6)$ & $24(9.2)$ \\
\hline Dyspnea & $23(9.4)$ & $22(13.6)$ & $26(6.6)$ & $26(10.0)$ \\
\hline Headache & $25(10.2)$ & $8(4.9)$ & $18(4.6)$ & $11(4.2)$ \\
\hline Serious adverse event $(s)^{\ddagger}$ & $87(35.7)$ & $60(37.0)$ & $107(27.2)$ & $67(25.7)$ \\
\hline Severe adverse event $(s)^{\S}$ & $84(34.4)$ & $44(27.2)$ & $90(22.8)$ & $55(21.1)$ \\
\hline Fatal adverse event(s) & $20(8.2)$ & $15(9.3)$ & $17(4.3)$ & $16(6.1)$ \\
\hline Adverse event(s) leading to treatment discontinuation" & $57(23.4)$ & $26(16.0)$ & $66(16.8)$ & $29(11.1)$ \\
\hline Diarrhea & $16(6.6)$ & $0(0.0)$ & $12(3.0)$ & $1(0.4)$ \\
\hline Progression of $\mathrm{IPF}^{\dagger}$ & $5(2.0)$ & $12(7.4)$ & $8(2.0)$ & $9(3.4)$ \\
\hline Nausea & $4(1.6)$ & $0(0.0)$ & $9(2.3)$ & $0(0.0)$ \\
\hline Pneumonia & $5(2.0)$ & $1(0.6)$ & $1(0.3)$ & $0(0.0)$ \\
\hline
\end{tabular}

Data shown are $n(\%)$ of patients in whom $\geq 1$ such event was reported

*Adverse events reported in $>10 \%$ of patients in any of the subgroups shown

${ }^{+}$Corresponds to Medical Dictionary for Regulatory Activities (MedDRA) term 'IPF', which included disease worsening and acute exacerbations of IPF

${ }^{\ddagger}$ An event that resulted in death, was immediately life-threatening, resulted in persistent or clinically significant disability or incapacity, required or prolonged

hospitalization, was related to a congenital anomaly or birth defect, or was deemed serious for any other reason

${ }^{\varsigma} \mathrm{An}$ event that was incapacitating or that caused an inability to work or to perform usual activities

"Adverse events leading to treatment discontinuation in $\geq 2 \%$ of patients in any of the subgroups shown

patients receiving anti-acid medication at baseline were at greater risk of infectious respiratory events (e.g. pneumonia) due to altered host defense against bacteria as a result of increased gastric $\mathrm{pH}$. In our analysis, pneumonia was reported in a numerically higher proportion of placebo-treated patients receiving anti-acid medication at baseline than placebo-treated patients who were not. Epidemiological data suggest a potential adverse relationship between proton pump inhibitor use and community acquired pneumonia [27-29], and a post-hoc analysis of data from placebo-treated patients in trials of pirfenidone suggested that in patients with $\mathrm{FVC}<70 \%$ predicted at baseline, unadjudicated pulmonary infections were more common in patients who were taking anti-acid medication at baseline [18, 19, 23].

The proportion of patients experiencing diarrhea adverse events was similar in the subgroups by anti-acid medication use at baseline, but in the nintedanib group, the frequency of permanent treatment discontinuations due to diarrhea, although low, was numerically higher in patients receiving anti-acid medication at baseline. Overall, the adverse event profile of nintedanib in patients in both subgroups by anti-acid medication use was as expected based on the safety and tolerability profile reported in the overall patient population [22].

\section{Conclusion}

In conclusion, this post-hoc analysis of data from the INPULSIS ${ }^{\bullet}$ trials showed that anti-acid medication use at baseline was not associated with a more favorable course of disease, and did not impact the treatment effect of nintedanib, in patients with IPF. Several hypotheses generated from this data warrant additional research, including prospective randomized clinical trials, to determine the role of acid and non-acid GERD in patients with interstitial lung diseases such as IPF and to 
characterize the benefits and risks of anti-acid medication in these patients. Further, the results of the WRAP-IPF trial (NCT01982968) will provide insights regarding the effects of laparoscopic anti-reflux surgery in patients with IPF.

\section{Additional files}

Additional file 1: Proton pump inhibitors and histamine-2 receptor antagonists used at baseline in patients taking anti-acid medications at baseline. (DOCX 17 kb)

Additional file 2: Comorbidities reported at baseline. (DOCX $18 \mathrm{~kb}$ ) Additional file 3: Severe, serious and fatal adverse events by subgroups. (DOCX $19 \mathrm{~kb}$ )

\section{Abbreviations}

DLCo: Diffusing capacity of the lungs for carbon monoxide; FVC: Forced vital capacity; GERD: Gastroesophageal reflux disease; HR: Hazard ratio; HRCT: High-resolution computed tomography; IPF: Idiopathic pulmonary fibrosis; SD: Standard deviation; SGRQ: St George's Respiratory Questionnaire

\section{Acknowledgments}

Medical writing assistance, supported financially by Boehringer Ingelheim, was provided by Julie Fleming and Wendy Morris of FleishmanHillard Fishburn, London, UK, during the preparation of this article. The authors were fully responsible for all content and editorial decisions, were involved at all stages of manuscript development, and have approved the final version of the manuscript, which reflects the authors' interpretation and conclusions. The authors received no compensation related to the development of the manuscript.

\section{Funding}

The INPULSIS ${ }^{\oplus}$ trials were funded by Boehringer Ingelheim.

\section{Availability of data and materials}

The datasets used and/or analyzed during the current study are available from the authors on reasonable request.

\section{Authors' contributions}

The authors meet criteria for authorship as recommended by the International Committee of Medical Journal Editors (ICMJE). All authors were involved in the drafting of the article and have read and approved the final version.

\section{Ethics approval and consent to participate}

The INPULSIS ${ }^{\circledR}$ trials were conducted in accordance with the principles of the Declaration of Helsinki and the Harmonized Tripartite Guideline for Good Clinical Practice from the International Conference on Harmonization and were approved by local authorities. The clinical protocol was approved by an independent ethics committee or institutional review board at each participating center. All patients provided written informed consent before study entry.

\section{Consent for publication}

Not applicable.

\section{Competing interests}

WS, RSH, and SSt are employees of Boehringer Ingelheim. UC has received grants, personal fees and non-financial support from Boehringer Ingelheim; grants, personal fees and non-financial support from Roche; personal fees from Bayer; and personal fees from GlaxoSmithKline, UCB Celltech, Biogen, FibroGen, and AstraZeneca. JB has received honoraria for lectures and for consulting from Boehringer Ingelheim, Actelion, Bayer and Roche, and is a member of national and international committees for guidelines in IPF and ILD. GR has provided consulting services for Boehringer Ingelheim, Biogen, Bristol-Myers Squibb, Gilead Sciences, FibroGen, Patara, Promedior, Sanofi, and Veracyte and has received research grant support from the National Institutes of Health, Bethesda, MD, USA for studies in IPF.

\section{Publisher's Note}

Springer Nature remains neutral with regard to jurisdictional claims in published maps and institutional affiliations.

\section{Author details}

${ }^{1}$ Ruhrlandklinik, University Hospital, University of Duisburg-Essen, Essen, Germany. ${ }^{2}$ Medizinische Klinik und Poliklinik V, University of Munich (LMU) and Asklepios Klinik München-Gauting, Member of the German Center for Lung Research, Munich, Germany. ${ }^{3}$ APHP, Hôpital Bichat, Service de Pneumologie A, DHU FIRE; INSERM, Unité 1152; Université Paris Diderot, Paris, France. ${ }^{4}$ Boehringer Ingelheim International $\mathrm{GmbH}$, Ingelheim am Rhein, Germany. ${ }^{5}$ Boehringer Ingelheim Pharmaceuticals Inc, Ridgefield, CT, USA. ${ }^{6}$ University of Washington, Seattle, WA, USA.

Received: 26 April 2018 Accepted: 20 August 2018

Published online: 03 September 2018

\section{References}

1. Raghu G, Collard HR, Egan JJ, Martinez FJ, Behr J, Brown KK, et al. An official ATS/ERS/JRS/ALAT statement: idiopathic pulmonary fibrosis: evidence-based guidelines for diagnosis and management. Am J Respir Crit Care Med. 2011; 183:788-824.

2. Fernandez IE, Eickelberg O. New cellular and molecular mechanisms of lung injury and fibrosis in idiopathic pulmonary fibrosis. Lancet. 2012;380:680-8.

3. Kim HJ, Perlman D, Tomic R. Natural history of idiopathic pulmonary fibrosis. Respir Med. 2015:109:661-70.

4. Collard HR, Ryerson CJ, Corte TJ, Jenkins G, Kondoh Y, Lederer DJ, et al. Acute exacerbation of idiopathic pulmonary fibrosis. An international working group report. Am J Respir Crit Care Med. 2016;194:265-75.

5. Raghu G, Amatto VC, Behr J, Stowasser S. Comorbidities in idiopathic pulmonary fibrosis patients: a systematic literature review. Eur Respir J. 2015:46:1113-30.

6. Behr J, Kreuter M, Hoeper MM, Wirtz H, Klotsche J, Koschel D, et al. Management of patients with idiopathic pulmonary fibrosis in clinical practice: the INSIGHTS-IPF registry. Eur Respir J. 2015;46:186-96.

7. Raghu G, Freudenberger TD, Yang S, Curtis JR, Spada C, Hayes J, et al. High prevalence of abnormal acid gastro-oesophageal reflux in idiopathic pulmonary fibrosis. Eur Respir J. 2006:27:136-42.

8. Lee JS, Song JW, Wolters PJ, Elicker BM, King TE Jr, Kim DS, Collard HR. Bronchoalveolar lavage pepsin in acute exacerbation of idiopathic pulmonary fibrosis. Eur Respir J. 2012;39:352-8.

9. Savarino E, Carbone R, Marabotto E, Furnari M, Sconfienza L, Ghio M, et al. Gastro-oesophageal reflux and gastric aspiration in idiopathic pulmonary fibrosis patients. Eur Respir J. 2013;42:1322-31.

10. Lee JS. The role of gastroesophageal reflux and microaspiration in idiopathic pulmonary fibrosis. Clin Pulm Med. 2014;21:81-5.

11. Raghu G, Meyer KC. Silent gastro-oesophageal reflux and microaspiration in IPF: mounting evidence for anti-reflux therapy? Eur Respir J. 2012;39:242-5.

12. Ghebre YT, Raghu G. Idiopathic pulmonary fibrosis: novel concepts of proton pump inhibitors as antifibrotic drugs. Am J Respir Crit Care Med. 2016:193:1345-52.

13. Beltramo G, Thabut G, Peron N, Nicaise P, Cazes A, Debray M-P, et al. Antiparietal cell autoimmunity is associated with an accelerated decline of lung function in IPF patients. Respir Med. 2018;135:15-21.

14. Lee JS, Ryu JH, Elicker BM, Lydell CP, Jones KD, Wolters PJ, et al. Gastroesophageal reflux therapy is associated with longer survival in patients with idiopathic pulmonary fibrosis. Am J Respir Crit Care Med. 2011:184:1390-4.

15. Lee JS, Collard HR, Anstrom KJ, Martinez FJ, Noth I, Roberts RS, et al. Antiacid treatment and disease progression in idiopathic pulmonary fibrosis: an analysis of data from three randomised controlled trials. Lancet Respir Med. 2013:1:369-76.

16. Raghu G, Morrow E, Collins BF, Ho LA, Hinojosa MW, Hayes JM, et al. Laparoscopic anti-reflux surgery for idiopathic pulmonary fibrosis at a single Centre. Eur Respir J. 2016:48:826-32.

17. Raghu G, Rochwerg B, Zhang Y, Garcia CA, Azuma A, Behr J, et al. An officia ATS/ERS/JRS/ALAT clinical practice guideline: treatment of idiopathic pulmonary fibrosis. An update of the 2011 clinical practice guideline. Am J Respir Crit Care Med. 2015:192:e3-19.

18. Raghu G. Anti-acid treatment in patients with IPF: interpret results from post-hoc, subgroup, and exploratory analyses with great caution. Lancet Respir Med. 2016:4:e46-7. 
19. Kreuter M, Wuyts W, Renzoni E, Koschel D, Maher TM, Kolb M, et al. Antiacid treatment in patients with IPF: interpret results from post-hoc, subgroup, and exploratory analyses with great caution - Authors' reply. Lancet Respir Med. 2016:4:e48.

20. Johannson KA, Strâmbu I, Ravaglia C, Grutters JC, Valenzuela C, Mogulkoc N, et al. Antacid therapy in idiopathic pulmonary fibrosis: more questions than answers? Lancet Respir Med. 2017;5:591-8.

21. Richeldi L, Costabel U, Selman M, Kim DS, Hansell DM, Nicholson AG, Brown KK, Flaherty KR, Noble PW, Raghu G, Brun M, Gupta A, Juhel N, Klüglich M, du Bois RM. Efficacy of a tyrosine kinase inhibitor in idiopathic pulmonary fibrosis. N Engl J Med. 2011;365:1079-87.

22. Richeldi L, du Bois RM, Raghu G, Azuma A, Brown KK, Costabel U, et al. Efficacy and safety of nintedanib in idiopathic pulmonary fibrosis. N Engl J Med. 2014;370:2071-82.

23. Kreuter M, Wuyts W, Renzoni E, Koschel D, Maher TM, Kolb M, et al. Antacid therapy and disease outcomes in idiopathic pulmonary fibrosis: a pooled analysis. Lancet Respir Med. 2016;4:381-9.

24. Kreuter M, Spagnolo P, Wuyts W, Renzoni E, Koschel D, Bonella F, et al. Antacid therapy and disease progression in patients with idiopathic pulmonary fibrosis who received pirfenidone. Respiration. 2017;93:415-23.

25. Collard HR, Richeldi L, Kim DS, Taniguchi H, Tschoepe I, Luisetti M, et al. Acute exacerbations in the INPULSIS trials of nintedanib in idiopathic pulmonary fibrosis. Eur Respir J. 2017;49 https://doi.org/10.1183/13993003. 01339-2016.

26. Raghu G, Yang ST, Spada C, Hayes J, Pellegrini CA. Sole treatment of acid gastroesophageal reflux in idiopathic pulmonary fibrosis: a case series. Chest. 2006;129:794-800.

27. Gulmez SE, Holm A, Frederiksen H, Jensen TG, Pedersen C, Hallas J. Use of proton pump inhibitors and the risk of community-acquired pneumonia: a population-based case-control study. Arch Intern Med. 2007;167:950-5.

28. Herzig SJ, Howell MD, Ngo LH, Marcantonio ER. Acid-suppressive medication use and the risk for hospital-acquired pneumonia. JAMA. 2009; 301:2120-8.

29. Giuliano C, Wilhelm SM, Kale-Pradhan PB. Are proton pump inhibitors associated with the development of community acquired pneumonia? A meta-analysis Expert Rev Clin Pharmacol. 2012;5:337-44.

Ready to submit your research? Choose BMC and benefit from:

- fast, convenient online submission

- thorough peer review by experienced researchers in your field

- rapid publication on acceptance

- support for research data, including large and complex data types

- gold Open Access which fosters wider collaboration and increased citations

- maximum visibility for your research: over $100 \mathrm{M}$ website views per year

At $\mathrm{BMC}$, research is always in progress.

Learn more biomedcentral.com/submissions 